\title{
Factors associated with sexual behavior among Sri Lankan adolescents
}

\author{
Nilusha Fernando ${ }^{1}$, Bilesha Perera ${ }^{2}$, Nayana Fernando ${ }^{2}$, Malik Gunawardana $^{2}$, Truls Østbye ${ }^{3}$ \\ ${ }^{1}$ Base hospital, Balapitiya, ${ }^{2}$ Faculty of Medicine, University of Ruhuna, Galle, ${ }^{3}$ Duke University Medical Center, \\ North Carolina, USA. \\ e-mail address of the corresponding author,Dr.Bilesha Perera: pperera@indiana.edu
}

\begin{abstract}
Introduction: Sexual behavior and reproductive health of adolescents in Sri Lanka is getting increasing attention. Factors associated with sexual behavior among adolescents are not adequately understood.

Objectives: To investigate the prevalence of sexual experiences among school age adolescents and assess demographic and behavioral correlates of sexual experience.

Methods: A study was conducted among late adolescents in public sector schools in southern Sri Lanka. A selfadministered questionnaire was used to obtain relevant information.

Results: Data from a total of 2385 subjects (1104 males and 1281 females) were analyzed. Among these, $15.5 \%$ of males and $7.9 \%$ of females reported some sexual experience with another person $(p<.01)$. Type of school (boys, girls or mixed), living with parents or not, family income, knowledge on sexual health, exposure to sexually explicit materials, and substance use were associated with report of sexual experiences in this sample of students. Availability and usage of counseling services in schools are not satisfactory.
\end{abstract}

Conclusions: A considerable proportion of late adolescents in the Southern Province have been sexually active. There is a need to address sexual health issues of this group through student education and parent education. Improving sexual life skills of students is an important component in sex education programs.

\section{Introduction}

Adolescence is a dynamic transition period during which many adolescents face health and relationship challenges. Among these challenges, sexual risktaking is one of the most prominent. Biological and psychological changes take place in the adolescents, and the concurrent demographic, epidemiological and cultural changes taking place in the society

make many adolescents vulnerable to sexual health risks $^{1-4}$. Such risks include sexual abuse, teenage pregnancies, preterm deliveries, stress, low selfesteem and psychological and relationship problems. Early puberty, the rising age at marriage, urbanization, availability of contraception, more freedom to move around with peers, family and social conflicts, intense exposure to sexual stimuli and the limited availability of sexual education and counseling services are some of the factors associated with sexual risk-taking behavior in adolescents in Sri Lanka ${ }^{2,5-7}$. On the other hand, sexual myths and taboos prevail in the country and too little guidance about sexuality have precluded many adolescents from being sexually healthy ${ }^{3}$.

Epidemiological data on sexual behavior among adolescents provide a basis for health and educational authorities to design and implement measures to reduce adverse consequences of sexual behavior in adolescents. A study was conducted by the Duke-Ruhuna collaborative research group at the Faculty of Medicine, University of Ruhuna, Galle to assess health behaviors among late adolescent school children in the Southern province. The prevalence of sexual behaviors and their associations with demographic and behavioral factors are reported in this paper. Based on the findings, several recommendations on how to improve sexual health among Sri Lankan adolescents are made. 


\section{Methods}

\section{Study population and sample}

The target population for the survey was older adolescents (aged 18 and over) in the three districts in Southern province. The study sample was drawn from advanced level students from all public schools (single sex as well as mixed sex) in the province. A cluster sampling method was used to select the participants ${ }^{8}$. Within the sampled schools, all Alevel classes (grade 11 and 12) were selected in the case of smaller schools; in larger schools, maximum of 7 classes were sampled. All students in the sampled classes were invited to take part in the survey. The response rate was over $95 \%$.

\section{Questionnaire and items}

A questionnaire, consisting of 138 items, was developed using common questions from similar surveys or validated scales. Demographic data included sex, age, religion, ethnicity, height and weight and parent's occupation, monthly income of the family and number of family members Questions relating to sexual issues included exposure to pornographic materials and "blue films", questions on normal biological processes such as menstrual cycle, masturbation and nocturnal ejaculation and question relating to how sexual problems may be resolved were also included. Students' views on sex education, and the availability of counseling services in the school system were also elicited. Those who reported heterosexual or homosexual experiences, with or without consent, at least once during their lifetime were labeled as having had a sexual experience Those who had smoked, or used alcohol or other drugs at least once during their life time were labeled as ever users. Knowledge of sexual issues was evaluated through 7 questions. Those who had been exposed to phonographic materials or blue films were categorized as having been exposed to sexually explicit materials. Three population health researchers confirmed the face validity of the questionnaire. The questionnaire was pilot tested on 40 students who were not part of the main study. The questionnaire took approximately 45 minutes to complete. It was first developed in English, translated to Sinhala and finally back translated to English. The Sinhala version was administrated to the students. The questionnaires were introduced and distributed by a group of 12 trained research assistants (science or art degree graduates). The respondents completed the questionnaire during a regular class period.

No personal identifiers were collected. Ethical approval for the survey was obtained from the Ethics Review Committee, Faculty of Medicine, Galle and from the Institutional Review Board, Duke University Medical Center, USA. Permission to conduct the survey in the selected schools was obtained from the Provincial Director of Education, Southern province and from the Principals in each selected school. Data entry was completed using Microsoft Excel. Statistical Package for Social Science (SPSS) was used for data analysis.

\section{Results}

Data from a total of 2385 respondents were analyzed. Of these, $53.7 \%(\mathrm{n}=1281)$ were females. Ninety eight percent $(n=2338)$ were SinhalaBuddhists. Nearly $98 \%$ of the participants were 18 years old. The respondents' family income was categorized into: lower (monthly income less than or equal to Rs. $10,000 /=$ ), middle (monthly income Rs. $10,001 /=$ - Rs. 30,000/=), and upper (monthly income greater than Rs. 30,000/=). Just over half $(51.5 \%)$ were from lower income families followed by middle income $(33.7 \%)$ and upper income families $(8.0 \%)$. Nearly $7 \%$ of the participants did not report family income. Of the total, $15.5 \%$ of males and $7.9 \%$ of females reported having had hetero- or homo-sexual experiences $(p<0.01)$.

Table 1 shows the associations between any sexual experience and demographic and behavioral factors by gender. 
Table1 - Demographic and behavioral correlates of sexual experience by gender

\begin{tabular}{|c|c|c|c|c|c|c|}
\hline & Prop & tion re & $\begin{array}{l}\text { rting havin } \\
\text { sexual expe }\end{array}$ & $\begin{array}{l}\text { any form } \\
\text { ce }\end{array}$ & & \\
\hline & & & & Fema & & \\
\hline & Percent (\%) & $\mathrm{N}$ & $(p \text { value })^{\dagger}$ & Percent $(\%)$ & $\mathrm{N}$ & $(p \text { value })^{\prime}$ \\
\hline School type & & & & & & \\
\hline Boys & $15.3 \%$ & 739 & 0.79 & $\ldots$ & $\ldots$ & $<0.01$ \\
\hline Girls & $\ldots$ & $\ldots$ & & $6.2 \%$ & 811 & \\
\hline Mixed & $15.9 \%$ & 365 & & $10.9 \%$ & 468 & \\
\hline Residence & & & & & & \\
\hline With parents & $14.0 \%$ & 968 & $<0.01$ & $7.2 \%$ & 1146 & 0.01 \\
\hline Without parent & $25.7 \%$ & 136 & & $14.1 \%$ & 135 & \\
\hline Familyincome & & & & & & \\
\hline Upper & $24.5 \%$ & 110 & 0.02 & $11.1 \%$ & 81 & 0.24 \\
\hline Middle & $14.1 \%$ & 427 & & $9.5 \%$ & 377 & \\
\hline Lower & $14.5 \%$ & 503 & & $7.2 \%$ & 726 & \\
\hline Knowledge of sexual health & & & & & & \\
\hline Average or good & $22.1 \%$ & 384 & $<0.01$ & $11.4 \%$ & 396 & $<0.01$ \\
\hline Poor & $11.9 \%$ & 720 & & $6.3 \%$ & 885 & \\
\hline Exposed to sexually explicit materi & & & & & & \\
\hline Yes & $19.5 \%$ & 846 & $<0.01$ & $17.1 \%$ & 292 & $<0.01$ \\
\hline No & $2.3 \%$ & 258 & & $5.2 \%$ & 989 & \\
\hline Substance use (ever) & & & & & & \\
\hline Yes & $19.9 \%$ & 573 & $<0.01$ & $8.9 \%$ & 429 & 0.35 \\
\hline No & $10.7 \%$ & 531 & & $7.4 \%$ & 852 & \\
\hline Watching TV (a normal school day) & & & & & & \\
\hline One hour or less & $16.4 \%$ & 440 & 0.51 & $7.2 \%$ & 676 & 0.37 \\
\hline More than one hour & $14.9 \%$ & 664 & & $8.6 \%$ & 605 & \\
\hline
\end{tabular}

${ }^{\dagger} \chi 2$ test for difference in proportions was used

Among males, there was no significant difference between boys schools and mixed schools in the proportion who reported having had hetero- or homo-sexual experiences. However, among females, significantly higher proportion of females in mixed schools reported having had hetero- or homo-sexual experiences compared to those in girls schools. Irrespective of the gender, the students who were living apart from their parents while schooling (either in boarding houses or with relatives etc.) were more likely to report sexual experiences than those living with their parents. Overall, a higher percentage of both males and females in upper income brackets reported sexual experiences, but this difference was only significant among males. Knowledge of sexual health and exposure to sexual stimuli were positively associated with sexual experience in both males and females. Having ever used substances was also positively associated with

sexual experience in males, but not in females. Time spent watching TV was not associated with sexual experience.

There was a gender difference with regard to seeking advice on sexual health issues. Among males, $60.6 \%$ and among females $44.5 \%$ were of the opinion that one could seek advice from peers about sexual health problems. Mother was the first choice for seeking sexual advice for $64.2 \%$ of females, but only for $16.7 \%$ of males, while peers were the first choice for $6.6 \%$ of females and for $23.9 \%$ of males. A medical doctor was the first choice for getting sexual advice for $5.8 \%$ of females and for $20.3 \%$ of males. In males, $51.4 \%$, and in females, $59.3 \%$ reported the presence of a student counselor or a student counseling service in their school. Among those who reported having a student counselor or a counseling service in their school, only $19.0 \%$ of 
males and $11.3 \%$ of females reported ever having used such a service.

\section{Discussion}

Significant proportions of late adolescents school boys and girls ( $15.5 \%$ of boys and $7.9 \%$ of girls) in this study sample reported having had some sexual experience. Underreporting bias is very likely when investigating sensitive issues such as sexual behavior, thus the actual figure may be higher than reported. Although there was no apparent difference in the percentages of males who were sexually active between this study and an island wide study conducted by the UNICEF ${ }^{9}$ on emerging issues among late adolescents (In the UNICEF study $13.9 \%$ and $18.2 \%$ of males aged 17-19 reported having had heterosexual and homosexual relations respectively), a higher percentage of females in our study reported having hetero and homosexual experiences compared to the UNICEF study (In the UNICEF study $2.2 \%$ and $3.6 \%$ of females aged 17 19 reported having had hetero and homosexual relations respectively). Geographical variations in sexual behavior may be one of the reasons for this observed difference.

Our findings indicate that the students in boys'schools and mixed schools, in general, are at increased risk of having had sexual experiences compared to those students in girls schools. One possible reason for this observed difference is that school boys likely have more freedom than school girls to be more socially mobile and interact with different types of peer groups. As expected, students who had been living with parents were less likely than others to report sexual experiences. Thus, parent supervision seems important factor in limiting student sexual activities. Students from upper income families were more likely than others to have had sexual experiences. Studies conducted in other countries have indicated a negative association between knowledge of sexual health and exposure to risky sexual behaviors ${ }^{10-12}$. However, our results indicate a positive association between the two variables. The reason may be that those students who have had sexual experiences may seek relevant knowledge on sexual health from various sources, thus may accumulate more information on sexual issues. Further research is needed to better understand this association. Exposure to sexually explicit materials seems to be a strong factor positively associated with sexual experiences reported by the participants. Although we did collect information about mobile phone use as part of our study, a significant proportion of school children in Sri Lanka now use mobile phones. It is easy to store sexually explicit materials in these phones and to exchange such materials with peers. Educational and health authorities may therefore want to investigate the usage of mobile phones in schools and possible adverse health effects of such usage. In boys, but not in girls, substance use is positively associated with sexual experiences. Thus, demographic variables such as school type, living conditions and family income, and behavioral factors such as substance use and exposure to sexually explicit materials need to be considered when designing sexual health education programs. Furthermore, these risk factors can be used to identify vulnerable groups.

It is notable that only a small proportion of students in the present study was motivated to seek advice from student counseling services. Nearly one forth of males sought advice from peers relating to sexual issues. To protect adolescents from unwanted sexual experiences, health and educational authorities, as well as parents, need to be proactive and provide information about sexual health to all adolescents rather than just discuss sexual issues with those adolescents who seek out medical advice or counseling after an unwanted pregnancy or psychological trauma. Proponents of the latter approach sometimes argue that sex education will stimulate students to experiment with sex, but evidence suggest that well planned sex education in fact delays sexual debut ${ }^{2,}{ }^{9-12}$. Sexual health education, as a primary prevention activity, has been identified as the most effective method for promoting healthy sexuality in adolescents and young adults ${ }^{11-14}$. Gender responsibility, adverse long term consequences of risky sexual behaviors, protection from possible cultural and environmental factors that make adolescents vulnerable to sexual risk taking, and discussions about where adolescents should seek sexual health advice from, should be the key components of such educational programs. Further, self-esteem and mental well being are other important issues that need to be covered in any sexual health education program for effective results. In this study, we observed that 
sexual health knowledge was positively associated with report of sexual experience. Since our study is cross sectional research we cannot identify the direction of the causation, but this association may reflect the fact that those who have had sexual experiences may subsequently seek advice and information to evaluate their sexual health risks. In any event, in addition to improving knowledge, lifeskill development is also essential to protect adolescents from negative sexual experiences.

\section{Conclusions and Recommendations}

The gender difference in sexual behavior observed in this study may be attributable to males having more general societal exposure, and exposure to sexual stimuli in particular, compared to females. Their greater experience with substances may also play a role. The results may imply that males are more vulnerable to being exposed to risky sexual activities including commercial sex and forced sex. Given that a considerable proportion of late adolescents in this study population are sexually active but not motivated to seek sexual health advice from trustworthy and reliable sources, there is a need to identify what factors bar them from seeking such advice.

Increasing awareness among teachers and parents about sexual health issues in adolescents, and identifying methods for developing life skills in students are important. Teachers and parents should be empowered with necessary knowledge and skills to identify groups at higher risks and direct such students to receive appropriate sexual health advice, and to receive treatment, if necessary. In this study, we did not investigate the age at first sexual experience of these participants. It is possible that some of the students who reported having had some form of sexual experience had experienced some form of coercion or even experienced forced experiences against their will ${ }^{2,3}$. Thus, sexual health education programs should enable students to identify situations where they possibly could get subjected to abuse, and improve skills to avoid such situations. Further, students should be encouraged to report any abusive or unwanted sexual experiences to parents, teachers, counselors or health professionals to minimize further events and adverse consequences. Finally, periodical evaluations of existing educational interventions are necessary to identify strengths and limitations to modify subsequent programs to obtain effective results.

\section{Acknowledgement}

This study was funded by the Tsunami Fund established by the Chancellor of Duke University Medical Center, and by the Hubert Yeargen Center for Global Health. Thanks to the research assistants for their help with the field work and the data collection.

\section{References}

1. World Health Organization. The second decade: Improving adolescent health and development, Geneva, Switzerland: WHO, 2001.

2. Goonawardane M. Teenage pregnancy. Sri Lanka Journal of Obstetrics and Gynecology, 2001, 23: 11-4.

3. Perera B, Reece M. Sexual behavior of young adults in Sri Lanka: Implications for HIV prevention, AIDS Care 2006, 18(5): 497-500.

4. Rosen JE. Adolescent health and development - A resource guide for World Bank operations staff and government counterparts, The World Bank, Washington DC, 2004.

5. Perera B, Fonseka PHG. Sexual behavior of advanced level students in Southern Sri Lanka. Journal of the College of Community Physicians of Sri Lanka 1998, 3: 13-17.

6. World Health Organization. World Health Report 2004, Geneva, Switzerland: WHO, 2004.

7. Senanayake P. Positive approaches to education for sexual health with examples from Asia and Africa. Journal of Adolescent Health 1992, 13(5): 351-4.

8. Bennett S, Woods T, Liyanage WM, Smith DL. A simplified general method for cluster sample surveys of health in developing countries. World Health Statistics Quarterly 1991, 44: 98-106.

9. United Nations International Children's Emergency Fund. National Survey on emergency issues among adolescents in Sri Lanka. Colombo, Sri Lanka: UNICEF, 2004.

10. Kirby D. School-based programs to reduce sexual risktaking behaviors. Journal of School Health 1992, 62(7): 280-7. 
11. Kirby D, Obasi A, Laris BA. The effectiveness of sex education and HIV education interventions in schools in developing countries. World Health organization Technical Report Series 2006, 938: 103-50.

12. Daboer JC, Oqbonna C, Jamda MA. Impact of health education on sexual risk behavior of secondary school students in Jos, Nigeria. Nigerian Journal of Medicine 2008, 17(3): 324-9.
13. De Silva WI, Somanathan A, Eriyagama V. Adolescent and youth reproductive health in Sri Lanka. Institute of Policy Studies in Sri Lanka, Colombo, 2003.

14. Smoak ND, Scott-Sheldon LA, Johnson BT, Carey MP. Sexual risk reduction interventions do not inadvertently increase the overall frequency of sexual behavior: a metaanalysis of 174 studies with 116,735 participants. Journal of Acquired Immune Deficiency Syndrome 2006; 41(3):374-84. 